\title{
Study on Comparison of Atmospheric and Vacuum Environment of Thermally-Induced Vibration Using Vacuum Chamber
}

\author{
Changduk Kong*, Hyunbum Park** and Haseaung Lee** \\ Department of Aerospace Engineering \\ Chosun University, Gwangju, Korea 501-759
}

\begin{abstract}
The present paper studies the thermally-induced vibration phenomenon of the flexible space boom structure. In order to simulate the thermally-induced vibration phenomenon of the flexible thin boom structure of the spacecraft with the attached tip mass in space, the thermally-induced vibration including thermal flutter is experimentally investigated at various thermal environments using a heating lamp in vacuum chamber. In this experimental study, fluctuating characteristics, natural frequency and thermal strains of the thermally-induced vibration are parametrically investigated at various thermal environment conditions. Finally the thermally-induced vibration of the flexible boom structure of the orbiting earth satellite in solar radiation environment from the earth eclipse region including umbra and penumbra is simulated using the power control of the heating lamp in the vacuum chamber.
\end{abstract}

Key Word : Vacuum chamber, Thermally-induced vibration, Natural frequency

\section{Introduction}

Space environmental tests of orbiting earth satellite at developmental stage, have become very important because of variety of complex activities the satellite needs to perform for precise target requirements. In space environment without gravity or with very small gravity, it is desirable to have lightweight space craft structure having high flexibility with low frequency and damping characteristic. The thermally-induced bending moment of the flexible structure by sunlight heating produces initial thermal deflection, accompanied by fluctuating moment due to periodic changes of sunlight incidence angle, causing oscillation. Therefore the spacecraft structure can be vibrated due to this periodic change of thermally-induced moment [1,2,3] .

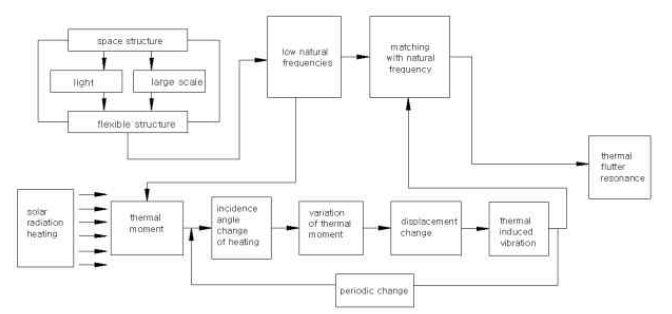

Fig. 1. Mechanism of thermally-induced vibration

\footnotetext{
* Professor

E-mail :cdgong@chosun.ac.kr

Tel : +82-62-230-7188 Fax : +82-62-230-7188

** Graduate Student
}

If the frequency of the thermally-induced vibration becomes the same as natural frequency, the resonance phenomenon appears. This resonance gives rise to various structural failure problems. Figure 1 shows a conceptual view of the mechanism of the thermally - induced vibration of the spacecraft structure in space environment. Solar panels or boom structures for global position measurement are generally thin and flexible. Many works of flexible structure have been studied $[4,5,6]$. The simplified thermal environment of a thin flexible tube boom is simulated for this study. Because thermal environment of the earth satellite is changed along with the flight path, the experimental tests simulate various thermal environmental conditions by a controllable heating lamp in vacuum chamber.

\section{Design and Manufacturing of Experimental Test Equipment}

\section{Vacuum environmental condition test system}

Figure 2 shows the thermally-induced vibratory simulation system of the flexible boom in atmospheric condition. Figure 3 shows the thermally-induced vibration simulation system of the flexible boom in vacuum condition which is to provide simulated space environments. 
The heating lamp capacity in vacuum chamber is maximum $2.5 \mathrm{~kW}$ class at $480 \mathrm{~V}$. The lamp is located at $80 \mathrm{~mm}$ apart from the boom, and radiation of the lamp heats up the boom surface. The concentrated tip mass of $50 \mathrm{~g}$ is attached at the end of the boom. A strain gage, which is the 120 ohm-FLA-5-23-1L of Tokyo Sokki Kenkyuju Co is attached on the surface positioned at $20 \mathrm{~mm}$ from the fixed end of boom specimen[7,8].

The specification of test specimen was presented in Table 1 . In order to protect the strain gage from the direct heating, a protection cover is provided shown as Figure 4. The $x$-directional strain is measured at $100 \mathrm{~Hz}$ using dynamic strain data recorder EDS-400A of KYOWA. Vacuum is measured by the VPRHS-OS-760 torr-4C sensor. The chamber is vacuumed to maximum 36 torr using the $16 \mathrm{VP}$-direct drive rotary vacuum pump $(0.4 \mathrm{~kW}, 4$ pole $)$ of HITACHICO.

In order to protect the $2.5 \mathrm{~kW}$ heating lamp from overheating, the lamp is cooled by cold water, and the internal surfaces of the vacuum chamber are painted by special heat protection paint, QT604 (L)-1999 (black color), to reduce the deflected light. Furthermore the sight window with two sheets of the $19 \mathrm{~mm}$ thickness strengthening glass is mounted on the vacuum chamber with supporting mounts and sealants.

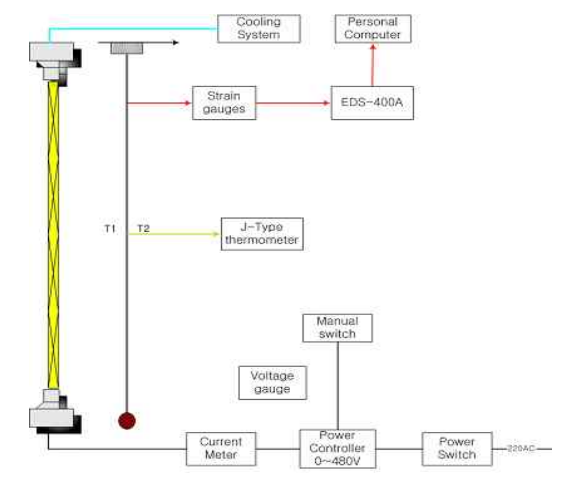

Fig. 2. Data acquisition and control system of thermally-induced vibration phenomena

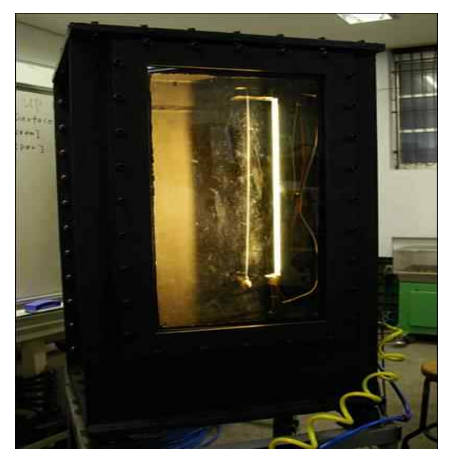

Fig. 3. Vacuum chamber for thermally-induced vibration test (500 width $\times 600$ depth $\times 1200$ length in $\mathrm{mm}$ )
Table 1. Specification of test specimen

\begin{tabular}{|l|c|}
\hline Material & Al alloy 2024 \\
\hline Length: $\mathrm{L}(\mathrm{mm})$ & 720.00 \\
\hline Diameter: $\mathrm{D}(\mathrm{mm})$ & 3.00 \\
\hline Thickness: $\mathrm{h}(\mathrm{mm})$ & 0.30 \\
\hline Distance from radiation heat source: $\mathrm{Z}(\mathrm{mm})$ & 80.00 \\
\hline Location of strain gage: Strain gage $(\mathrm{mm})$ & 20.00 \\
\hline
\end{tabular}

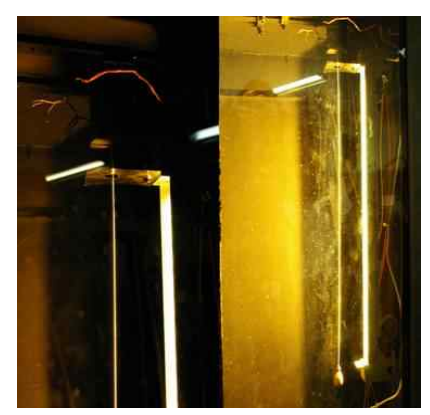

Fig. 4. Protection cover from direct heating and fixing mount of boom

Thermal environmental conditions can be adjusted by various voltage changes such as $120 \mathrm{~V}$, $240 \mathrm{~V}$ and $440 \mathrm{~V}$, and variation of fluctuating characteristic times is measured. After measuring vibratory fluctuating characteristics, heating is stopped just before the boom tip mass hits the lamp, and then the damping characteristics are investigated. Here fluctuating characteristic time defines as the time between starting of oscillation and hitting to the lamp. Furthermore thermal environmental conditions are adjusted by controlling the lamp power. In order to keep accuracy, three tests per condition are carried out. Natural frequencies are obtained experimental data by FFT analyzer using MATLAB program.

\section{Experimental results and discussion}

In both vacuum (36 torr) and atmospheric (753 torr) conditions, natural frequencies, initial thermal strains and vibratory fluctuating characteristic time of the boom are measured. The measuring results are compared at periodic changes of thermal environmental conditions. Table 2 shows initial thermal strains at different thermal environmental conditions with 625W, 1250W and $2290 \mathrm{~W}$ of lamp power in vacuum and atmosphere. As shown in the Table 2, the thermal strains at $625 \mathrm{~W}$ of lamp power are same in both vacuum and atmospheric conditions, but thermal strains in vacuum at higher lamp powers increase and the strains in atmosphere at higher lamp powers decrease inversely. It may be considered that the reduced temperature difference ratio between front and back surfaces by convection in air reduces the thermally-induced bending moment. 
Table 2. Initial thermal strains at different thermal environmental conditions in vacuum and atmosphere

\begin{tabular}{|c|c|c|}
\hline $\begin{array}{c}\text { Lamp power } \\
(\mathrm{W})\end{array}$ & $\begin{array}{c}\text { Strain in } \\
\text { vacuum }(\mu)\end{array}$ & $\begin{array}{c}\text { Strain in atmospheric } \\
(\mu)\end{array}$ \\
\hline 625 & 120 & 120 \\
\hline 1250 & 260 & 190 \\
\hline 2290 & 300 & 80 \\
\hline
\end{tabular}

Table 3. Vibration fluctuating characteristic at different thermal environmental conditions in vacuum and atmosphere

\begin{tabular}{|c|c|c|}
\hline $\begin{array}{c}\text { Lamp power } \\
(\mathrm{W})\end{array}$ & $\begin{array}{c}\text { Fluctuating } \\
\text { characteristic time } \\
\text { in vacuum (sec) }\end{array}$ & $\begin{array}{c}\text { Fluctuating } \\
\text { characteristic time } \\
\text { in atmosphere (sec) }\end{array}$ \\
\hline 625 & 700 & 400 \\
\hline 1250 & 350 & 170 \\
\hline 2290 & 140 & 90 \\
\hline
\end{tabular}

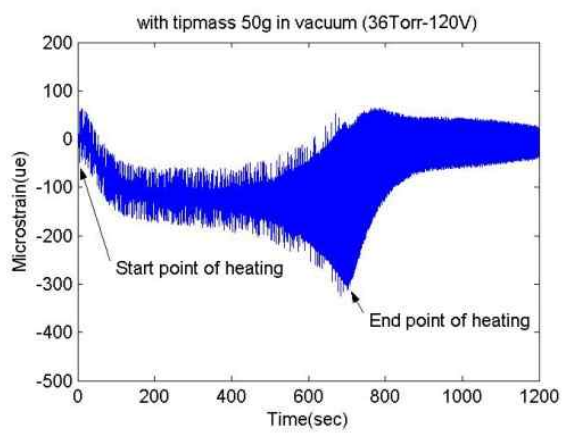

(a) $36 \mathrm{Torr}-120 \mathrm{v}$

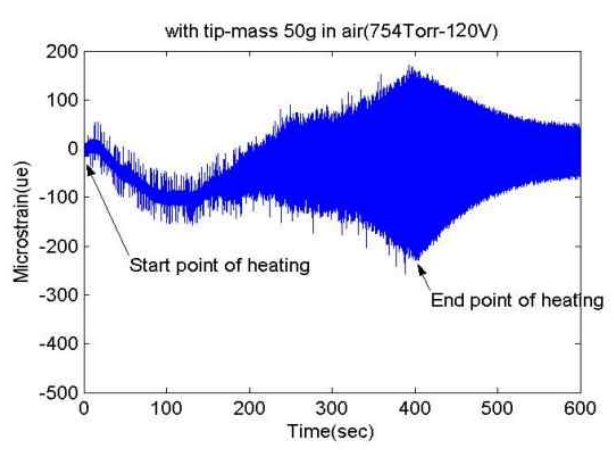

b) 754 Torr $-120 \mathrm{v}$

Fig. 5. Variation of thermal strains measured at $625 \mathrm{~W}-120 \mathrm{~V}$ lamp power in vacuum and atmospheric

Table 3 shows vibration fluctuating characteristic times at different conditions with 3 lamp power cases in vacuum and atmosphere. Vibration fluctuating characteristic time at both vacuum and air decreases with increases of lamp power. However the fluctuating characteristic times in atmosphere are much faster than those in

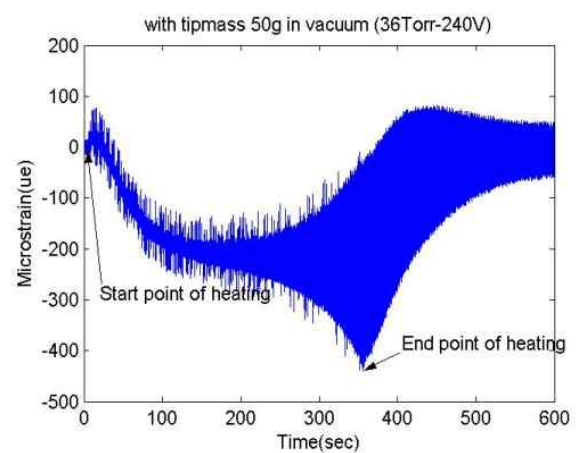

(a) $36 \mathrm{Torr}-120 \mathrm{v}$

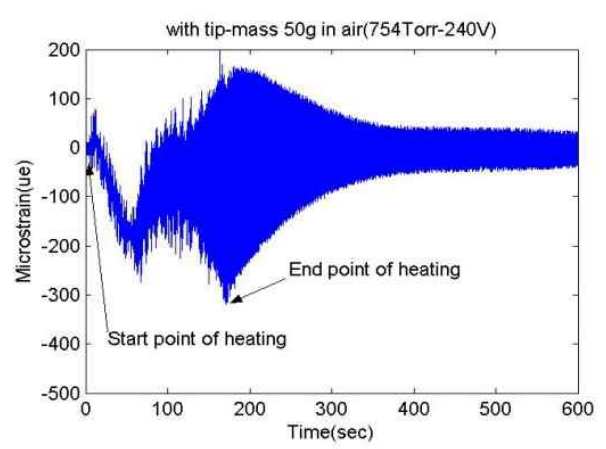

(b) 754 Torr $-240 \mathrm{v}$

Fig. 6. Variation of thermal strains measured at $1250 \mathrm{~W}-240 \mathrm{~V}$ lamp power in vacuum and atmosphere

vacuum. It may be assumed that the second mode natural frequencies in air can accelerate rapidly the fluctuating characteristic phenomena. Figure 5, 6 and 7 show experimental test results at different thermal environmental conditions such as $625 \mathrm{~W}$, $1250 \mathrm{~W}$ and $2290 \mathrm{~W}$ of lamp power in vacuum and atmosphere, which are previously explained at Table 2 and 3. As shown in figures, it is found that the overall thermally-induced vibration patterns at both vacuum and atmospheric conditions are clearly different, however vibration fluctuating characteristic patterns are almost same in spite of different lamp power conditions except for the fluctuating characteristic time.

In this study, modal analysis of the thermally-induced vibration is performed by the finite element method. The FEM model uses 6481 shell elements with $50 \mathrm{~g}$ tip mass and one end fixed boundary condition. [9] And a linear temperature distribution from front face $\left(255^{\circ} \mathrm{C}\right)$ to back face $\left(205^{\circ} \mathrm{C}\right)$ of the boom tube is assumed. Figure 8 and 9 show modal analysis results for the first and second flap modes and their natural frequencies. 


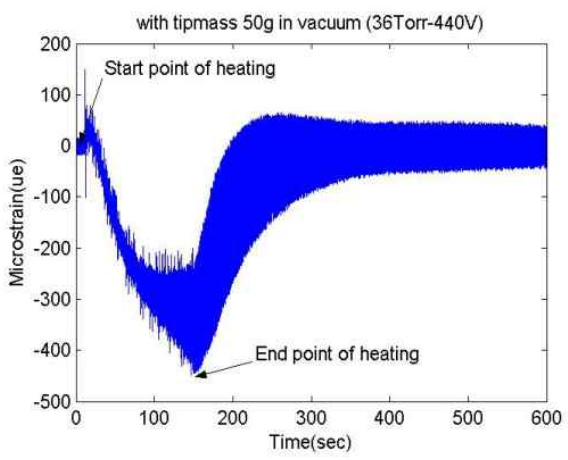

(a) $36 \mathrm{Torr}-440 \mathrm{v}$

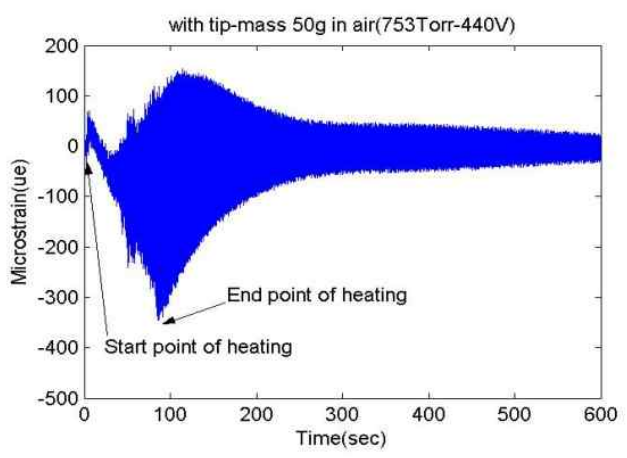

(b) 753 Torr $-440 \mathrm{v}$

Fig. 7. Variation of thermal strains measured at $2290 \mathrm{~W}-440 \mathrm{~V}$ lamp power in vacuum and atmosphere

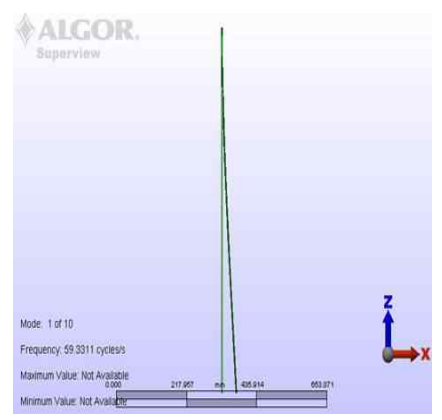

Fig. 8. First flap mode shape and natural frequency

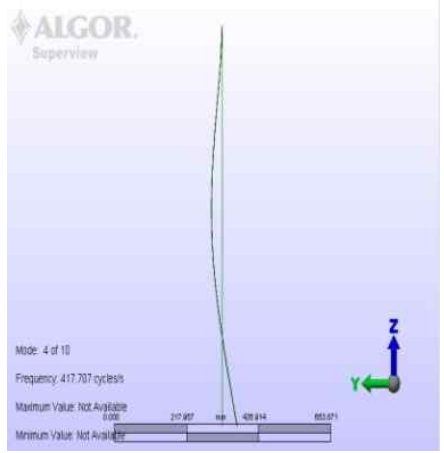

Fig. 9. Second flap mode shape and natural frequency
Table 4. Comparison between measured and predicted natural frequencies

\begin{tabular}{|c|c|c|}
\hline Mode shape & Analysis results & Test results \\
\hline First flap mode & $59.33 \mathrm{~Hz}$ & $58.59 \mathrm{~Hz}$ \\
\hline Second flap mode & $417.7 \mathrm{~Hz}$ & $419.92 \mathrm{~Hz}$ \\
\hline
\end{tabular}

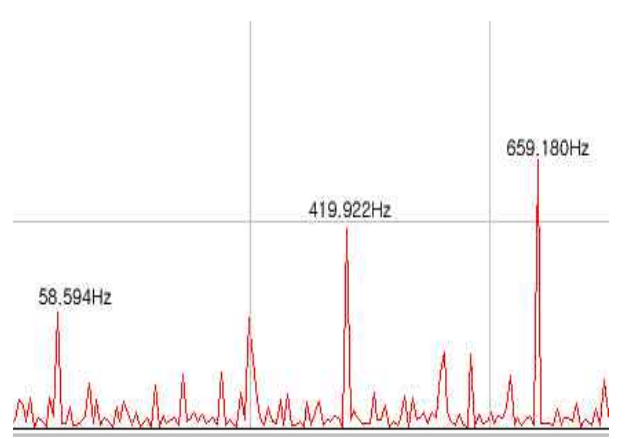

Fig. 10. The result of FFT analysis

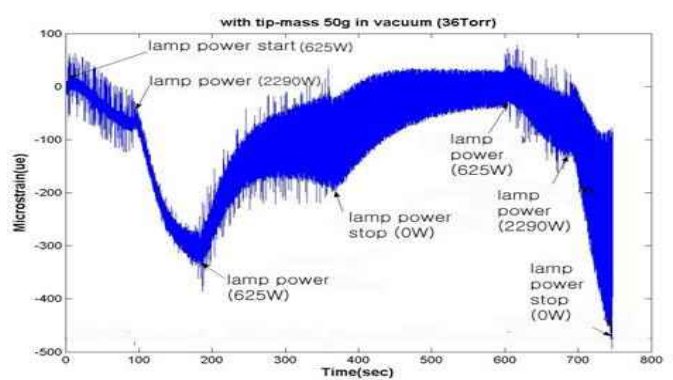

Fig. 11. Variation of thermal strains of the boom due to periodic change of thermal environments in vacuum followed with $0 \mathrm{~V}-120 \mathrm{~V}-440 \mathrm{~V}-$ 120V-440V-0V (Specimen length: $715 \mathrm{~mm}$ )

Table 4 shows natural frequencies of the thermallyinduced vibration of the boom at thermal environmental condition as 2290W of lamp power in vacuum condition. Here experimental natural frequencies are obtained by FFT analyzer using measured thermal strains shown as Figure10. Table 4 shows that the analysis values are in good agreement with the measured values. And it was found that the thermal flutters in both vacuum and atmosphere have all the first flap mode shapes, but the flutter mode in air combines with the $2^{\text {nd }}$ flapmode.

In order to simulate the flight condition of the orbiting earth orbit satellite, thermal environmental conditions are generated with the lamp power control followed by the input voltage setting sequence such as $0 \mathrm{~V}-120 \mathrm{~V}-440 \mathrm{~V}-120 \mathrm{~V}-$ OV-120V-440V-0V shown in Figure 11. As shown in figures, when the thermal strain approaches to maximum at $625 \mathrm{~W}$ of the lamp power, then the lamp power increases to $2290 \mathrm{~W}$. 
After reaching to maximum strain at $2290 \mathrm{~W}$, the thermally-induced vibration is generated. However, if the lamp power decreases to $625 \mathrm{~W}$ thermallyinduced vibration is diverged, but thermal strain is reduced. Through this simulated experimented tests, it was confirmed that if the flexible boom structure of the orbiting earth satellite with the thermally-induced vibration is reentered into solar radiation environment, then vibration is rapidly diverged and structural failure appears due to abrupt thermal deformation.

In order to investigate the effect of the specimen length, thermally-induced vibration specimen tests with different lengths (i.e. $720 \mathrm{~mm}$, $715 \mathrm{~mm}$ ) at the same condition are performed. Figure 10 and 11 show that fluctuating characteristic time of the shorter specimen increases relatively to the longer specimen

\section{Conclusions}

In this study, the thermally-induced vibration including thermal flutter of the flexible boom with the concentrated tip mass was experimentally investigated at various thermal environments in both vacuum and atmosphere. The fluctuating characteristic of the thermally-induced vibration in vacuum was relatively slower due to pure radiation heating, but it was relatively faster in atmosphere due to convective thermally disturbance and the second mode natural frequency was additionally generated. Thermal strains were relatively larger in vacuum due to direct radiation heating on the boom surface, but they were relatively smaller in atmosphere due to partial thermal loss by heating surrounding atmosphere of boom surface. The first mode natural frequencies were constant at all thermal environments and both in vacuum and in atmosphere. Abrupt thermal environmental change of the flexible boom with residual thermal induced vibration can generate rapidly the thermal flutter. It means that if the flexible boom structure of the orbiting earth satellite with the residual thermally induced vibration is reentered into solar radiation environment from the earth eclipse region including umbra and penumbra, then the thermally inducedvibration is rapidly diverged and therefore finally structural failure can appear or the life time of the satellite can be reduced due to energy consumption for vibration or position controls.

\section{References}

1. Richard S. Foster, "Thermally Induced Vibrations of Spacecraft booms ", Ph.D.Thesis, VirginiaUniversity,U.S.A,1998.

2. John Johnston, "Thermally-Induced Dynamics of Spacecraft Structures", NASA GSFC Sep. 2, 1999.

3. Thornton, E. A. and Paul, D. B.,

" Thermal-Structural Analysis of Large Space Structures: An Assessment of Recent Advances” , Journal of Spacecraft and Rockets, Vol. 22, No 4,1985, pp. 385-393.

4. Kraus, H. P., " Thermally Induced Vibration of Thin Nonshallow Spherical Shell”, AIAA Journal, Vol. 4, 1966.

5. Y. K. Jang and D. H. Lee, "Design Engineering of Spacecraft System”, Kyungmoon Publishing Co., 1999.

6. I. S. Yoon, "Study on Thermal Stability of Space Craft flexible Structure, Ph. D. Thesis, Chungnam University, 2002.

7. S. Sumi et al., "Thermally-Induced Bending Vibration of Thin-Walled Boom with Tip Mass - Analysis for the Experiments under Laboratory Conditions " Tech. Report of KyushuUniv.,Vol. 63,No.1,1990.

8. C. D. Kong, K. W. Oh and Y. Sugiyama,

"A Study on Thermally-Induced Vibration of Flexible Space Structures”, KSAS, Vol. 31, No. 9, 2003.

9. ALGOR Tutorials, Samwon Millennia, 2005. 